\title{
Biopolítica, gênero e organismos internacionais: mercado dos direitos das mulheres ${ }^{\star}$
}

\author{
Flávia Cristina Silveira Lemos, ${ }^{\star}$ Franco Farias da Cruz, Leandro Passarinho Reis Junior, \\ Válber Sampaio, Amanda Pereira de Carvalho Cruz, Michelle Ribeiro Côrrea
}

Universidade Federal do Pará, Belém, PA, Brasil

\section{Resumo}

Este artigo tem o objetivo de analisar práticas de governo das mulheres pela UNESCO e UNICEF a partir da perspectiva histórica e documental. Efetua-se uma crítica à instrumentalidade dos direitos das mesmas pelo gerenciamento neoliberal. Interroga-se a vertente do empreendedorismo proposto por estes organismos e também é analisado como estes órgãos regulam os corpos de mulheres pelas relações familiares, pela conjugalidade e pela educação dos filhos. Por fim, são problematizadas as articulações entre ações sexistas, o atravessamento de uma racionalidade biológica de gênero e o empoderamentos das mulheres na política para mediar conflitos na comunidade, em nome da segurança.

Palavras-chave: mulheres; biopolitica; empreendedorismo; gênero; sexismo.

\section{Biopolitics, gender and international organizations: market for women's rights}

\begin{abstract}
This article aims to analyze governance practices of women by UNESCO and UNICEF from the historical and documentary perspective. Makes up a critique of instrumentality of the rights of same by the neoliberal management and wonders whether the present entrepreneurship proposed by these organizations. It is also analyzed how these bodies governing bodies of women through family relationships, marital and for the education of children. Finally, are problematized the links between gender actions, the crossing of a biological rationality of gender and the empowerments of women in politics to mediate conflicts in the community on behalf of the security.
\end{abstract}

Keywords: women; biopolitics; entrepreneurship; gender; sexism.

\section{Introdução}

Sob a rubrica de empoderamento/protagonismo de mulheres, diversas organizações internacionais, agências multilaterais, bancos e ONGs propõem a formação de um mercado de supostas habilidades e competências ditas femininas. Os direitos são mercantilizados e transformados em oportunidades econômicas e sociais de trabalho informal para geração de renda nessa lógica difundida por estes órgãos e entidades, articuladamente com equipamentos e organizações brasileiras.

Diversos organismos internacionais têm recomendado que as mulheres entrem no mercado da geração de renda por meio da proposta de empreendimentos complementares na família e pelo empresariamento de supostas habilidades consideradas femininas, historicamente por uma sociedade machista, quais sejam: as atividades domésticas, de culinária, de artesanato, de cuidado e coleta de frutos e ervas. Estas iniciativas figuram como afirmação de direitos e empoderamento de mulheres para estes órgãos e seriam vistas enquanto protetivas da família, de acordo com os assessores destas agências multilaterais.

Organismos como o Fundo das Nações Unidas para a Infância (UNICEF) e a Organização das Nações Unidas para a Educação, ciência e cultura (UNESCO) têm instrumentalizado o conceito de relações de gênero como

\footnotetext{
^Financiamento: CNPQ

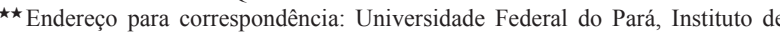
filosofia e ciências humanas. Rua Augusto Corrêa, 01 - Guamá. Belem, PA Brasil. CEP: 66075110. E-mail: flavazevedo@bol.com.br, francofcruz@ yahoo.com.br, 1passarinho28@gmail.com, valbersampaio@hotmail.com
}

diferença biológica: feminino (mulher) e masculino (homem). Uma série de políticas públicas e de propostas para a criação de novas e/ou ampliação das existentes é sempre relacionada pelos dois organismos internacionais à mulher como sexo biológico, como cuidadora, afetuosa, pacífica e educadora.

Estes dois organismos são bastante sexistas, defendem que a mulher é promotora da paz mundial, por exemplo, devendo ocupar cargos políticos por este motivo. Enquanto o homem é relacionado à violência e ao crime, ao sexo sem prevenção e ao uso de drogas. A mulher como mãe, esposa e mediadora de conflitos na comunidade e na sociedade é constituída como uma imagem sagrada e salvadora desde que aceite as recomendações ordeiras e moralistas de uma condição de gênero submissa e medicalizada, dedicada, doce, disciplinada e pacífica.

Por exemplo, para o UNICEF, a mãe deve brincar com os filhos e o pai também porque eles fazem brincadeiras diferentes em função de gênero, um brinca com afeto e o outro com iniciativa. Esta afirmativa reproduz estereótipos de gênero e se torna sexista ao invés de colaborar para romper estes preconceitos. Para a UNESCO, quando a mãe se divorcia, tem dificuldades de cuidar dos filhos e lhes dar limite, o que aumenta os fatores de risco da família entrar em vulnerabilidade e dos filhos supostamente desenvolverem algum tipo de desvio social grave. Ou seja, o marido homem seria dessa maneira o que dá 
limites aos filhos e o principal provedor e assegurador da família em termos de respeito e autoridade, novamente, denotando estigma e preconceitos de gênero.

Ao estudar documentos desses órgãos há alguns anos já, em um enfoque histórico genealógico, baseado em contribuições de Foucault (2008), Castel (1987) e Deleuze (1992), neste artigo, foi selecionado o campo gênero e sexualidade especificamente de uma pesquisa mais ampla a respeito da atuação do UNICEF e da UNESCO no Brasil. Uma perspectiva da histórica cultural e da psicologia social institucional tem guiado os trabalhos de pesquisa que realizamos com a problematização dos relatórios dessas agências multilaterais.

Os documentos analisados estão disponíveis na página na internet dessas organizações e podem ser baixados sem nenhum custo. O recorte temporal é a Nova República Brasileira, ou seja, o período que vai da abertura política na redemocratização até o presente. Em termos de critério espacial, foi escolhido o Brasil, pois estes organismos promovem ações em muitos países e interessa estudar as prescrições e articulações políticas que ocorrem no Brasil especificamente.

Foucault (2008), no curso "Nascimento da Biopolítica" assinalou que as relações afetivas entre pais e filhos, de conjugalidade entre outras de proximidade passaram a ser alvo de capitalização, na economia política neoliberal. As relações se tornaram contratos firmados tais como um empreendimento e investimento a realizar, avaliar e assegurar e ampliar para extrair mais benefícios do que custos, na biopolítica.

Em Nascimento da Biopolítica, Foucault (2008) relata que há no neoliberalismo um incentivo para o trabalho informal que não gera salário e sim renda. Ainda destaca que o pequeno crédito para habitação e para o empreendedorismo é promovido para auxiliar as famílias como uma política social denominada de gestão de riscos.

Também assinalou como os neoliberais apregoavam a importância de fazer do artesanato, do turismo e da pequena agricultura familiar um alvo de governamentalidade para a criação de investimentos na geração de renda enquanto um empreendimento econômico e político relacionado ao sujeito de direitos concomitantemente.

Para Foucault (2008), o neoliberalismo é caracterizado como uma maneira de regular as condutas incentivando a livre-concorrência e o mercado, com a diminuição de responsabilidades do Estado e aumento das do cidadão. A política de crédito na economia política neoliberal é contínua para promover subjetividades empreendedoras com incentivos de geração de renda ao invés de gerador de empregos com salários.

A família é vista como uma unidade empreendedora que contratualiza duas relações pelo cálculo de custo e benefício e se avalia permanentemente como espaço de produção de investimentos descentralizados no campo e na criação artesanal. O Estado deve oferecer regras para garantir a liberdade de transação entre indivíduos empresas. A teoria do capital humano passa a reger as relações de educação, de trabalho e afetivas, sendo fomentadas em todos os espaços sociais e nas relações de gênero e familiares.

O sujeito de direitos se torna menos importante que o econômico e, quando é ativado sempre o é para figurar como mercado e empresa da cidadania. A tutela civil é negociada o tempo todo pela gestão de perdas e danos na esfera da chamada estabilidade de uma governabilidade econômica e política no cenário nacional e mundial. Há um cálculo de interesses nos processos de tomada de decisão por meio de comitês e associações, de consultores e delegados que são chamados a representar segmentos da população.

\section{UNICEF e UNESCO: organismos multilaterais, neoliberalismo e direitos}

A UNESCO foi criada em 1945. Após as grandes guerras mundiais e a existência dos regimes totalitários, emerge se denominando agente de uma missão: a promoção da paz como vetor de garantia dos direitos humanos. Difunde a ideia de que a guerra nasceria na mente dos homens, devendo ser preventivamente evitada nesse campo por meio de políticas de educação, ciência e cultura.

Passa a realizar uma espécie de vigilância internacional para buscar a defesa da paz com a cooperação entre os países integrantes. Visa garantir a cidadania, solidariedade, bem-estar social e justiça por meio da educação, da ciência e da cultura. No Brasil, instala seu primeiro escritório, em Brasília, em 1972, iniciando suas atividades. A UNESCO passará a expandir suas ações, em 1990 com a Declaração Mundial sobre Educação para Todos. A partir da década de noventa, no século XX, resolve articular uma forte aliança com o Ministério da Educação em prol da implantação de inúmeras recomendações específicas ao Brasil.

Após essa primeira parceria, também estabeleceu contatos próximos com: o Ministério da Ciência e da Tecnologia, da Justiça, do Meio Ambiente, do Trabalho e com o Ministério das Comunicações. Além desses órgãos, se articula com bastante incidência com as organizações não governamentais e o Banco Mundial. Atualmente, situa suas práticas no Brasil com os seguintes setores: Educação, Cultura, Ciência, Tecnologia, Comunicação, Informática, Meio Ambiente, Direitos Humanos e Gestão Social. Seu prédio fica próximo a esses ministérios e basicamente age em constante parceria com os mesmos, em editais de pesquisa, na publicação de materiais diversos e com o incentivo à implementação de uma série de políticas na educação, na ciência e na cultura.

Com os Ministérios: da Agricultura, da Educação, do Meio Ambiente e da Cultura juntamente com a Secretaria de políticas para as mulheres vem propondo projetos de desenvolvimento e empoderamento local, visando cooperar com a formulação de políticas públicas que tenham como eixo os pactos, acordos, declarações e carta internacionais de direitos humanos; assinadas pelos Estados-membros relacionados aos direitos das mulheres, associadamente ao das crianças e adolescentes. Para alcançar sua missão, a UNESCO publica relatórios e livros para divulgar seus ideais e propostas políticas para a educação brasileira. 
Age com frequência juntamente com o Programa das Nações Unidas para o Desenvolvimento (PNUD), com o Fundo de Desenvolvimento das Nações Unidas para as Mulheres (UNIFEM), com o Programa das Nações Unidas para o Meio Ambiente (PNUMA), o Fundo das Nações Unidas para a Infância (UNICEF), com a Organização Mundial de Saúde (OMS) e com a Organização das Nações Unidas para a Alimentação e Agricultura (FAO) e com o Programa das Nações Unidas para a População (UNFPA).

Este campo de equipamentos e organizações, entidades e agências formam o que Castells (1999) classificou como sociedade em rede. As práticas vão sendo articuladas em um entrecruzamento complexo de forças e agenciamentos políticos com efeitos mútuos e que opera a fabricação de legitimidades para as organizações ligadas às Nações Unidas.

No Brasil, os estudos de Gohn (2010) sobre movimentos sociais vêm assinalando que cada vez mais se tem campanhas de mobilização em rede e menos práticas de movimentos sociais ampliadas e com força política. $\mathrm{Na}$ visão dessa autora, a rede opera mais mobilização e articulação e menos incidência crítica. Esta afirmativa é interessante porque os organismos internacionais realizam intensa mobilização de entidades, órgãos e equipamentos, mas não operam criticamente frente aos mesmos. Portanto, não podem ser denominados de movimentos sociais e sim de organizações que agem em redes de mobilizações sociais.

O UNICEF está ligado à Organização das Nações Unidas (ONU) também. No Brasil, sedia escritórios nas capitais e tem um escritório central em Brasília, localizado na sede do Ministério da Saúde. Atua no país desde a década de cinquenta, no século XX. Primeiramente, agindo no cuidado das crianças órfãs da guerra; na sequência, dirigindo seu foco para a saúde materno-infantil e; posteriormente, ampliando-a para a promoção, a garantia e a defesa de direitos das crianças e adolescentes.

Entre as ações realizadas pelo UNICEF, estão as seguintes: publica relatórios com indicadores; realiza recomendações para diminuir as violações de direitos; organiza conferências; divulga declarações e pactos internacionais; tenta fazer uma intensa articulação política com o objetivo de incidir nos países integrantes. Os seus assessores escrevem textos analíticos sobre os indicadores de proteção à saúde materno infantil e sobre a situação da infância e da adolescência brasileira. O UNICEF financia alguns projetos e premia os programas e projetos que classifica como boas práticas; compara os indicadores e prescreve metas.

Os relatórios do UNICEF estão divididos por temas, fotos, tabelas estatísticas, por comentários e análises, entrevistas, falas dos embaixadores e artistas que oferecem sua imagem para defender direitos e tem seções semelhantes aos manuais de conduta para a mãe, para a família, infância e adolescência. Os relatórios do UNICEF são resultado de uma imensa rede articulada com ressonâncias micro e macropolíticas.
A dimensão de gênero será incorporada pela UNESCO e pelo UNICEF a partir dos anos 2000 em diante. Praticamente vincula gênero às mulheres e ambos operam práticas que nomeiam de fortalecimento da cidadania econômica e social das mesmas. Fazem isto juntamente com uma associação permanente da figura da mulher à maternidade e à conjugalidade.

A igualdade de gênero é relacionada ao plano da entrada da mulher no mercado pelo empoderamento empresarial com o desenvolvimento social local. Gohn (2004) destaca que o termo empoderamento se tornou um chavão nos discursos em políticas públicas e de assessores das mesmas, durante os anos iniciais do século XXI. Está relacionado à ideia dos pressupostos de desenvolvimento sustentável e tem sido difundido por organizações internacionais e pela mediação de especialistas para a produção de projetos locais. Neste sentido, vale apontar que o empoderamento enquanto tática se aproxima no neoliberalismo da designada responsabilidade social, que utilitariamente opera uma articulação entre público e privado no plano do financiamento, regulação e execução de políticas sociais e educativas.

\section{Mulheres e o governo da família para as organizações internacionais}

As mulheres para o UNICEF e UNESCO aparecem constantemente vinculadas à família e aos filhos. Quando divorciadas são definidas como vulneráveis e se tem filhos, estes são apresentados como em risco de se tornarem violentos e cometerem infrações pela situação suposta de vulnerabilidade de integrarem uma família chefiada por mulher. A concepção de que a família é base da sociedade, e que a criança é o elemento central, devendo receber todas as atenções dos pais aparece, com frequência, nas práticas desses organismos.

Especialistas materializam suas receitas com prescrição de regras para mulheres, mães, adolescentes e crianças com recorrência nos relatórios do UNICEF e da UNESCO. Há uma afirmação dos discursos dos especialistas frente à família, à mulher considerada desinformada e que viola direitos e tem seus direitos violados por precisar de capacitação, por carecer de habilidades e competências que são oferecidas nos manuais de cuidado dos dois organismos internacionais citados.

Assim, a chamada capacitação das mulheres ganha estatuto de prioridade na agenda política desses órgãos. Para ambos, grande parte da problemática da violação de direitos, da violência e da pobreza seria resolvida com formação. Os técnicos prescrevem a importância da mãe se fundamentar na ciência para salvaguardar a tarefa educacional dos filhos em prol da promoção do desenvolvimento infantil, publicando materiais, organizando congressos e ampliando a rede de controle das famílias na proteção das crianças e adolescentes.

Mas está claro que é fundamental a existência de redes sociais para apoiar as famílias a cuidar de suas crianças. Essas redes, apoiadas por governos, organizações da sociedade civil e principalmente das comunidades, devem ser capazes de engajar as famílias em processos de aprendizado e aqui- 
sição de habilidades para cuidar das crianças em casa [...] (FUNDO DAS NAÇÕES UNIDAS PARA A INFÂNCIA [UNICEF], 2001, p. 11).

Os cuidados afetivos, educativos e de saúde que a família proporciona à mulher gestante e à criança nos seus primeiros anos de vida são decisivos para seu desenvolvimento integral e para garantir um bom começo de vida [...]. Para atingir as crianças e os adolescentes nas suas três fases de vida, a principal parceira do UNICEF é a família. [...] O UNICEF, com outros parceiros, prioriza a família: organiza campanhas, produz materiais educativos, apoia projetos de prevenção da violência contra meninas e meninos dentro do ambiente familiar, estimula programas de capacitação das famílias. (UNICEF, 2002, p. 3)

Nos seus primeiros anos de vida, a principal referência da criança é a família com a qual ela vive. É da família que ela vai receber apoio afetivo, alimentação, cuidados de saúde e que ela vai aprender a falar, brincar, cantar, interagir com os outros. A criança precisa do pai e da mãe. Homens e mulheres estimulam-na de maneira diferente. [...] Cuidar de crianças pequenas não é fácil. O UNICEF procura ajudar as famílias a lidar da melhor forma possível com as crianças de até 6 anos de idade. Para isso as famílias são capacitadas para ensinar os filhos cuidados com saúde e higiene, alimentação equilibrada com micronutrientes e para estimular as crianças física e psicologicamente. O UNICEF produz materiais de orientação para os pais e capacita agentes comunitários de saúde, que repassam essas informações para as famílias. (UNICEF, 2002, p. 9).

A premissa de que a família deve ser fortalecida é central para essas organizações como uma política social permanente e em rede. No interior da família UNICEF e UNESCO consideram que a mãe é uma mediadora entre a família com o Estado e com as organizações internacionais. As práticas estas organizações se voltam para o financiamento e suporte técnico aos projetos de capacitação das famílias através de agentes comunitários e da produção de cartilhas. Os saberes psicopedagógicos, de higiene, sobre amamentação e nutrição estão na base desses manuais de conduta.

Há uma proliferação discursiva prescrevendo como a mulher como mãe e esposa deve gerir sua família. A prática de governo das condutas por meio de conceitos, tais como: risco, vulnerabilidade, resiliência e desenvolvimento; frequentemente está apresentada nos relatórios da UNESCO e do UNICEF. Assim, acompanhamos que os saberes maternos e das mulheres são desvalorizados frente à fala autorizada e o discurso competente dos assessores e especialistas. É possível afirmar com Deleuze (1992) que a ciência aplicada pelas recomendações dos relatórios de organismos internacionais por meio dos discursos dos especialistas, no âmbito das regulações de conduta se tornou uma vedete no mercado dos direitos e no marketing empresarial e de si, no contemporâneo.

Esta política é nomeada de desenvolvimento das habilidades e competências da família. Para essas agências internacionais, cuidado é uma competência e uma habilidade que opera pelas relações familiares com a comunidade e, depois, com o Estado e que ocorre por meio da materialidade de processos de desenvolvimento humano. A ausência de informações das mulheres pobres e com baixa escolaridade impediria a estimulação precoce e a promoção do desenvolvimento chamado biopsicossocial da criança seria a principal causa de situações de violação dos direitos das crianças para o UNICEF e UNESCO.

Ainda implicaria em iniquidades para as mulheres adultas em função da situação de vulnerabilidade em que esta ficaria por não ter acesso à escolarização. Ora, mais o que é risco e vulnerabilidade? Castel (1987) fez uma relevante crítica à gestão de risco e vulnerabilidade nas políticas contemporâneas pelo preconceito que atravessa esse tipo de governo das condutas na medida em que risco é virtualidade e não generalização estatística. Esta problematização feita por este sociólogo pode no auxiliar a problematizar as práticas de governo de riscos na regulação dos corpos de mulheres, no Brasil pela UNESCO e UNICEF. Dessa maneira, ainda com Castel (1987, 2005), podemos perceber a construção de um negócio do social pela gestão de risco, que pressupõe a produção de sociedades de insegurança a serviço do incremento da indústria da segurança e de um mercado do risco e perigo.

[...] nos primeiros anos de vida das crianças, [...] seus pais e familiares são suas mais importantes, quando não únicas referências (UNICEF, 2001, p. 11).

O ideal é que as mães sejam maduras para cuidar de seus filhos. [...] Os cuidados têm que começar antes mesmo da criança nascer. A mulher grávida precisa fazer pelo menos seis consultas pré-natais e de orientações sobre como garantir o melhor começo de vida de seu bebê. Os pais, outros familiares e toda a comunidade devem participar do desenvolvimento da criança desde a gestação. Nos seus primeiros anos de vida, a principal referência da criança é a família com a qual ela vive. É da família que ela vai receber apoio afetivo, alimentação, cuidados de saúde e que ela vai aprender a falar, brincar, cantar, interagir com os outros. A criança precisa do pai e da mãe. Homens e mulheres estimulam-na de maneira diferente. A criança também precisa de serviços públicos que garantam sua saúde, educação, lazer e que protejam seus direitos. (UNICEF, 2002, p. 9).

Para garantir o que os consultores do UNICEF denominam um "bom começo de vida", a criança deve crescer em um "ambiente familiar seguro e tranquilo" (UNICEF, 2001, p. 9). Para o órgão citado, os estímulos e cuidados oferecidos pelos pais e familiares da criança, nos primeiros anos de vida, bem como a idade e escolaridade destes pais, o aleitamento materno e a imunização através das vacinas seriam os principais norteadores da promoção do desenvolvimento infantil. A UNESCO formula o conceito de desenvolvimento socioafetivo como importante na educação das crianças e adolescentes pela família e incentiva que trabalhadores sociais e escolas ofertem o ensino dessas competências afetivas e sociais às mulheres mães, às famílias e à comunidade.

Foucault (1988), ao analisar a biopolítica, apontou que esta tinha uma preocupação no controle procriativo das condutas e na histericização dos corpos das mulheres. A política da vida opera um governo das mulheres que passa pela gestão do corpo, da sexualidade da dimensão de uma 
construção de gênero. As mulheres são colocadas no plano biológico de procriar e, no aspecto emocional são infantilizadas, devendo ser alvo de políticas de capacitação e de escolarização para que saibam cuidar dos filhos gerados, conforme os saberes da biomedicina e da psicopedagogia.

Na biopolítica enquanto governo da vida em nome da saúde, da força das nações e da segurança mundial. Com efeito, estas práticas acionam racismos de Estado e sociedade, segundo Foucault (1988; 1999). Destarte, é possível problematizar a relação dos racismos presentes nas políticas sociais voltadas às mulheres no plano da cultura e das relações sociais pelos processos de padronização e regulação que são exercidos pelas agências internacionais mencionadas nesse artigo.

Frente à racionalidade racista na biopolítica é possível analisar criticamente os efeitos de apropriação da Teoria da Carência Cultural, formulada nos Estados Unidos, durante os anos sessenta do século XX, no Brasil. Segundo Patto (1999), esta teoria foi apropriada no país em outros da América Latina, durante a Guerra Fria e Ditadura Civil-Militar brasileira. Por meio desse pensamento, tanto na educação quanto nas políticas de saúde e sociais foram incorporados pressupostos dessa teoria. A ideia de carência cultural, afetiva e intelectual era recorrente usada para explicar: a pobreza, a baixa escolaridade, a reprovação na escola, o desemprego, a violência, o adoecimento e diversas situações consideradas desvios sociais.

Nessa teoria, são mesclados componentes racistas de ordem biológica e cultural que produziriam um lugar de privação para determinados grupos e famílias, hierarquizando valores e corpos, classificados pelo negativo e, portanto, estigmatizados.

As diferenças eram traduzidas em desigualdades naturalizadas por uma noção de natureza humana. A biopolítica se efetua justamente nessa dimensão em que mulheres e seus filhos, seus modos de vida e suas realidades são apresentadas enquanto subalternas e inferiores, devendo se submeter à tutela da política social compensatória neoliberal pelo empresariamento de seus corpos ditos em risco como uma forma de sobrevivência frente às mazelas e dificuldades experimentadas por uma sociedade que concentra renda, discrimina, estigmatiza e impede o acesso às oportunidades.

Essas práticas das agências supracitadas estão em uma linha de proposta educativa pragmática, utilitarista, reprodutivista, tecnicista e flexível, sem crítica e baseada em uma sociedade da informação, conforme aponta Frigotto $(1994,2006)$. A escola e a formação devem oferecer informações para serem usadas instrumentalmente na docilidade política dos corpos e com objetivos de produtividade e não para pensar e forjar atitudes críticas. As mulheres são convidadas à capacitação para educar os filhos e realizar o planejamento familiar, para cuidar da casa e dos maridos e não para pensarem e produzirem liberdades das tutelas das políticas compensatórias.

Para a UNESCO e UNICEF, as situações de pobreza e de diminuição do poder aquisitivo por divórcio, as mulheres seriam levadas às dificuldades em manter a famí- lia, educar os filhos e zelar por sua saúde. Tais fatos são vistos pelos assessores desses organismos, em seus cálculos políticos e econômicos a postular que essa situação, se ampliada e generalizada pode comprometer o futuro dos filhos, gerar violências, produzir diversos problemas em efeito cascata para o país e para o mundo, na visão sistêmica desses órgãos. Os discursos produtores de estigmas imputados às famílias pobres ganham nomes de carência, deficiência, desorganização, privação cultural e biológica (NICOLACI-DA-COSTA, 1987).

As múltiplas carências e dificuldades que a pobreza gera afetam excessivamente as possibilidades de sobrevivência e provocam a desarticulação de famílias inteiras. Existem muitas evidências dessa tendência. O número de lares onde o único chefe de família é a mãe tem crescido assustadoramente. $\mathrm{O}$ número de crianças que são levadas pelas suas famílias ao trabalho, ou que são realmente forçadas a tomar essa iniciativa para sua subsistência, tem aumentado. [...] O número de filhos extraconjugais também tem crescido. Da mesma forma, segundo estudos recentes, a pobreza exerce influência significativa sobre o aumento do número de mães adolescentes. O estresse socioeconômico é um dos elementos que está tendo efeitos sobre um problema que só vem intensificando-se: o da violência doméstica. Ela causa sérios danos às crianças. [...] Por sua vez, aqueles que sofrem violência doméstica nos seus lares tendem a repeti-las depois nas suas próprias famílias. Uma manifestação extrema do quadro de enfraquecimento, de erosão e de crise que caracteriza a situação de muitas famílias pobres é o aumento da população de crianças que moram nas ruas. Uma das principais causas desse problema reside na impossibilidade de a família prover um ambiente adequado mínimo aos seus filhos. (UNESCO, 2003, p. 38-39).

Uma culpabilização das famílias pobres e das mulheres mães é materializada com essa racionalidade expressa nos documentos interrogados nas pesquisas que temos feito durante mais de dez anos de estudo histórico. Nesse plano da culpabilização operada pela UNESCO e pelo UNICEF, podemos entender porque Guattari e Rolnik (2005) ressaltaram que o capitalismo mundial integrado individualiza as desigualdades sociais e econômicas, direcionando a culpa às famílias e indivíduos. Deleuze (1992) também assinala como o capitalismo de especulação produziu uma sociedade de endividamento face às encomendas que os corpos recebem ininterruptamente e parecem jamais dar conta das mesmas, tamanhas são as infindáveis cobranças, prescrições e processos de culpabilização diante do não cumprimento das normas, leis, recomendações e supostas obrigações apresentadas às famílias, trabalhadores e aos estudantes.

A sujeição sofrida pelas mulheres em nome da autonomia de gênero opera o paradoxo da reiteração do sexismo, dessa maneira. UNESCO e UNICEF constroem a mulher mãe e esposa enquanto a responsável pelas problemáticas sofridas pela família e comunidade. Atribuem às mulheres a responsabilidade de promover a saúde e a educação na família, partindo de racionalidades que podemos nomear como biopolíticas. 
A influência positiva de um componente fundamental do capital social - a família -, em numerosos aspectos, tem sido verificada por várias pesquisas recentes. Quanto maior a solidez desse capital social básico; melhores os resultados e vice-versa (UNESCO, 2008, p. 57).

Aprender a ser, para melhor desenvolver a sua personalidade e estar à altura de agir com cada vez maior capacidade de autonomia, de discernimento e de responsabilidade pessoal. Para isso, não negligenciar na educação nenhuma das potencialidades de cada indivíduo: memória, raciocínio, sentido estético, capacidades físicas, aptidão para comunicar-se. (UNESCO, 2006, p. 102).

Práticas de planejamento familiar, da aprendizagem psicopedagógica para auxiliar os filhos, de economia doméstica para ajudar o esposo na renda e ainda, a participação em cooperativas e pequenas empresas são prescrições dessas organizações internacionais que operam pelo chamado empoderamento de mulheres. Nesse sentido, mulheres têm sido chamadas a tornar empreendimento supostas habilidades e competências do lar e ditas femininas por organizações internacionais em parceria com equipamentos brasileiros em nome do empoderamento para reduzir a pobreza.

Santos e Lemos (2011) interrogaram o utilitarismo presente no uso do conceito de empoderamento de mulheres pelas organizações não governamentais articuladas ao Estado para promover programas de cunho compensatório com vistas ao desenvolvimento econômico e social enquanto uma vitrine de política social de gestão dos riscos virtualmente, no neoliberalismo. O empreendedorismo é difundido como uma segunda chave para diminuir uma cultura ligada à pobreza e à violação de direitos após a primeira chave que seria a capacitação para aquisição de conhecimentos preventivos e propulsores de geração de renda.

\section{Mulheres, família e desenvolvimento da comunidade como capital social}

O discurso do desenvolvimento da comunidade ressalta a importância de que a própria comunidade se una para resolver seus problemas, promovendo a educação de seus integrantes, em especial, dos jovens para ocupar lugares de responsabilidade em projetos locais que visem resolver demandas específicas. A ideia de desenvolvimento da comunidade, no Brasil e da família como elemento chave no processo de integração dos indivíduos à ordem social vigente. A exaltação da comunidade é vista, a partir do final do século XX como uma utopia de união entre os povos, no processo de globalização. O desenvolvimento da comunidade estava embasado em um viés preventivo, tendo na educação sua fonte de difusão principal. Todos deveriam concentrar esforços para manter a estabilidade social, integrando os indivíduos dispersos e rebeldes a esta lógica, sendo que a família, a mulher e a comunidade são solicitadas na tarefa de executar o governo de crianças e adolescentes (AMMANN, 2003).

O contexto local ganha destaque no incentivo do desenvolvimento da comunidade e os organismos internacionais começam a estimular e motivar os pequenos grupos a unirem-se em prol da resolução de seus problemas, ao invés de reivindicar direitos e lutar pela garantia destes. A ideia era assegurar o controle social através de uma educação para a paz e do convite à participação de maneira acrítica e apolítica.

A coesão social é um objetivo da UNESCO que é acionado continuamente sob o prisma de um amplo esforço para afirmar a concórdia entre os povos e os diferentes grupos sociais. No caso, a educação seria um instrumento funcionalista de integração social, na visão dos assessores desse organismo internacional. Ou seja, a UNESCO visa à paz como um motor de uma economia, pautada na concorrência mundial que deveria ser aceita sem conflitos e tensões por todos.

Fundamentalmente, a UNESCO estará servindo à paz e a compreensão entre os homens, ao valorizar a educação como espírito de concórdia, de emergência de um querer viver juntos como militantes da nossa aldeia global que há que pensar e organizar, para bem das gerações futuras. Deste modo, estará contribuindo para uma cultura da paz (UNESCO, 2006, p. 31).

A UNESCO pode contribuir muito, através da educação, para a abertura dos espíritos, aos deveres da solidariedade internacional. Agora que as organizações internacionais e as nações se preparam para os grandes desafios do século XXI a cidadania mundial continua a ser um conceito muito afastado das realidades e percepções concretas. A aldeia global é, contudo, o nosso horizonte à medida que as interdependências se multiplicam e que os problemas se mundializam (UNESCO, 2006, p. 207).

As práticas culturais locais são apropriadas pelos organismos internacionais em busca do fomento econômico pelo capital social na gerência dos corpos de mulheres. Seus saberes ligados às ervas, à culinária regional e ao artesanato local passa a ser alvo da educação destas organizações em prol de uma lógica empresarial em nome da garantia de direitos e da redução da pobreza e de supostos riscos sociais.

Assim, a defesa de projetos que sejam mediadores do consenso pela gerência da cultura é uma ação de relevância para os assessores desse organismo multilateral pelo empoderamento de mulheres que deverão gerar a paz social e a renda da família pela criação de cooperativas e de pequenos empreendimentos locais. As políticas públicas para a educação, no país, cada vez mais incorporam a temática da diversidade ao campo dos direitos humanos, em um projeto de inclusão social. Foram iniciadas na educação infantil e se intensificaram ao longo de uma educação permanente, atravessada pelos eixos de pluralidade e de garantia de direitos enquanto um mercado a empreender para evitar gastos com políticas de atendimento às famílias pobres bem como para promover seu capital social por meio do voluntariado da comunidade e do associativismo de mulheres em prol da sociedade (ROSEMBERG, 2013).

Torna-se urgente superar os mitos, passar para a ação, unir esforços, e enfrentar a pobreza e a iniquidade com um investimento social sustentado, administrado com critérios 
avançados de gerenciamento social, e projetado para potencializar as pessoas, o principal recurso e o fim último de toda sociedade democrática. (UNESCO, 2003, p. 152).

A Pastoral da Criança é um projeto-referência para todo o atendimento em saúde e educação a famílias e crianças. Com o trabalho de mais de 127 mil líderes comunitários voluntários, movidos pela solidariedade e pela fé, a Pastoral transforma as comunidades onde atua (UNICEF, 2001, p. 31).

Assim, ao trazer gênero e sexualidade para o currículo, o UNICEF e a UNESCO esvaziam a dimensão de luta dos movimentos sociais nestas temáticas e apropriam parte da demanda das lutas feministas de maneira instrumental e utilitarista, deslocando o chamado empoderamento de mulheres para fins securitários, econômicos, políticos e medicalizantes dos corpos das mesmas.

De acordo com Silva (1994), o pensamento neoliberal no plano das políticas educacionais transforma em mercadoria o ato de ensinar e aprender, em um evidente conservadorismo cultural. Uma internacionalização do governo, em prol da segurança, tece-se e se expande sob a forma de administração da paz mundial, gerenciada por peritos das Organizações das Nações Unidas, conectados a uma rede de outras instituições, em escala planetária, em nome da proteção e garantia dos direitos humanos.

A família transforma-se no espaço onde as crianças desenvolvem sua inteligência emocional e capacidade crítico-criativa, e forma hábitos de saúde preventiva. Da mesma forma, ela surge nitidamente como a principal estrutura de prevenção da delinquência. O papel que ela pode desempenhar no campo moral é fundamental. Diversas pesquisas comparativas revelam as estreitas relações existentes entre a delinquência juvenil e famílias desarticuladas. [...] Como romper com esse círculo e resgatar o imenso potencial da família? Diferentemente do que acontece na América Latina, em alguns países mais avançados do mundo existem, na atualidade, vigorosas políticas de proteção direta á família. Enxerga-se a família como um direito essencial, como um dos sustentáculos de um tecido social sadio, e uma base estratégica para o desenvolvimento econômico (UNESCO, 2003, p. 40-41).

A pobreza destrói sistematicamente as famílias, e ataca particularmente as mulheres. [...] A gravidez precoce tem sido outra fonte distintiva na conformação de famílias pobres onde a mulher tem que assumir a subsistência. Esse tipo de família apresenta desde o início, uma grande vulnerabilidade. (UNESCO, 2003, p. 117).

Atrela-se a este modelo a ideia de modernização e promoção da paz social. A ONU através de suas agências passa a atuar junto aos diversos setores da sociedade, com a oferta de projetos de extensão da Universidade, junto às cooperativas e, também junto aos representantes de igrejas, sobretudo dos movimentos eclesiais de base. O objetivo principal era acionar estratégias de ajustamento social das populações que potencializavam qualquer tipo de ameaça à ordem social. As mulheres são convidadas a participar da mediação de conflitos nas comunidades por serem concebidas pelo UNICEF e pela UNESCO como pacíficas e afetivas.

Fractal, Rev. Psicol., v. 27 - n. 3, p. 203-210, 2015
A visão comunitarista dessas agências pode ser criticada pelas análises de Bauman (1999) e Foucault (2008), em que ambos interrogam como a mundialização neoliberal operou a promoção dos associativismos em identificações comunitárias para fazer destes investimentos locais com impacto global. A separação de segmentos de uma população e não de um povo assinala o aspecto biopolítico dos organismos internacionais, pois estes estratificam em amostras os grupos, os nomeando pela estatística e demografia, pela epidemiologia e economia política, deslocando a figura do povo para a população e de gênero para mulheres enquanto seres biológicos. A cidadania vai para um segundo plano frente à economia política e a busca de segurança mundial.

As mulheres são nessa lógica comunitária um segmento da população, mais empreendedoras e mediadoras de conflitos do que cidadãs e povo; ou seja, não podem ser participativas de fato e sim capitalizadas socialmente desde que enquadradas nos estereótipos desses organismos internacionais em prol do desenvolvimento das comunidades e da construção da paz global pelas alianças e consensos locais.

\section{Considerações finais}

A mulher foi escolhida como uma agente de manutenção da ordem, logo seu papel era enaltecido e considerado de suma relevância, pois, para os positivistas e também para os funcionalistas, a ordem era um pré-requisito para que o progresso se tornasse uma realidade. A população deveria ser convocada para esquecer todas as diferenças de classe, etnia, gênero, faixa etária, credo político e religioso, para resolver os problemas coletivos e propiciar o bem-estar da comunidade, se unindo para o enfrentamento de seus problemas.

$\mathrm{Na}$ atuação designada como de proteção às crianças e aos adolescentes, a família e, em especial, a mãe é apresentada como a instituição da maior importância para a coesão social. Privilegia-se a educação da mulher e mãe como agente central de manutenção da ordem no espaço familiar e como instrumento de gestão da criança e do jovem. Utiliza-se a gestão dos corpos de mulheres para governar a família e a prole como um todo.

Em nome da paz social e da ordem econômica liberal, UNICEF e UNESCO acriticamente e utilitariamente buscam regular a vida e os corpos das mulheres. As orientam e incentivam a educação formal das mesmas pelo menos até o ensino fundamental e médio para que elas saibam realizar o planejamento familiar, cuidar dos filhos e da casa, de acordo com os princípios higienistas.

Ammann (2003) ressalta que a mulher se tornou a guardiã moral da comunidade e da sociedade para os organismos internacionais. Foi caracterizada por estes enquanto ser que deve ser venerada como mãe, dona de casa e esposa benevolente. Por isto, os economistas e administradores políticos passaram a recomendar o desenvolvimento comunitário mediado pelo empoderamento das mulheres em prol da capitalização dessas supostas características e atributos ditos femininos. 


\section{Referências}

AMMANN, S. B. Ideologia do desenvolvimento da comunidade no Brasil. 10. ed. São Paulo: Cortez, 2003.

BAUMAN, Z. Globalização: as consequências humanas. Rio de Janeiro: J. Zahar, 1999.

CASTEL, R. A gestão dos riscos: da antipsiquiatria à póspsicanálise. Rio de Janeiro: Francisco Alves, 1987.

CASTEL, R. A insegurança social: o que é ser protegido? Petrópolis, RJ: Vozes, 2005.

CASTElls, M. A sociedade em rede. São Paulo: Paz e Terra, 1999. v. 1.

DELEUZE, G. Conversações. Rio de janeiro: Editora 34, 1992.

FOUCAULT, M. História da sexualidade: a vontade de saber. Rio de Janeiro: Graal, 1988. v. 1.

FOUCAULT, M. Em defesa da sociedade. São Paulo: Martins Fontes, 1999.

FOUCAULT, M. Nascimento da Biopolítica. São Paulo: Martins Fontes, 2008.

FRIGOTTO, G. Educação e formação humana: ajuste neoconservador e alternativa democrática. In: GENTILI, P. A. A.; SILVA, T. T. da (Org.). Neoliberalismo, qualidade total e educação: visões críticas. 5. ed. Petrópolis, RJ: Vozes, 1994. p. 11-27.

FRIGOTTO, G. A produtividade da escola improdutiva. 8. ed. São Paulo: Cortez, 2006.

FUNDO DAS NAÇÕES UNIDAS PARA A INFÂNCIA. Situação da infância brasileira. Brasília, DF: UNICEF, 2001.

FUNDO DAS NAÇÕES UNIDAS PARA A INFÂNCIA. Fazer valer os direitos das crianças e dos adolescentes. Brasília, DF: UNICEF, 2002.

GOHN, M. Empoderamento e participação da comunidade em políticas sociais. Saúde e Sociedade, [S.1.], v. 13, n. 2, p. 20-31, 2004.

GOHN, M. da G. Movimentos sociais e redes de mobilizações civis no Brasil contemporâneo. Petrópolis, RJ: Vozes, 2010.

GUATTARI, F.; ROLNIK, S. Micropolítica: cartografias do desejo. Petrópolis, RJ: Vozes, 2005.

NICOLACI-DA-COSTA, A. M. Sujeito e cotidiano: um estudo da dimensão psicológica do social. Rio de Janeiro: Campus, 1987.

ORGANIZAÇÃO DAS NAÇÕES UNIDAS PARA A EDUCAÇÃO, A CIÊNCIA E A CULTURA. Declaração Mundial sobre Educação para Todos: plano de ação para satisfazer as necessidades básicas de aprendizagem. Jomtien: UNESCO, 1990.

ORGANIZAÇÃO DAS NAÇÕES UNIDAS PARA A EDUCAÇÃO, A CIÊNCIA E A CULTURA. Por uma economia com face mais humana. Brasília: UNESCO, 2003.

ORGANIZAÇÃO DAS NAÇÕES UNIDAS PARA A EDUCAÇÃO, A CIÊNCIA E A CULTURA. Relatório Jacques Delors. Educação para o século XXI: um tesouro a descobrir. Brasília, DF: Cortez/MEC/UNESCO, 2006.

ORGANIZAÇÃO DAS NAÇÕES UNIDAS PARA A EDUCAÇÃO, A CIÊNCIA E A CULTURA. Mais ética, mais desenvolvimento. Brasília, DF: UNESCO, 2008.
PATTO, M. H. S. A produção do fracasso escolar: histórias de submissão e rebeldia. São Paulo: Casa do Psicólogo, 1999.

ROSEMBERG, F. Mulheres educadas e a educação de mulheres. In: PINSKY, C. B.; PEDRO, J. M. (Org.). Nova história das mulheres no Brasil. São Paulo: Contexto, 2013. p. 332-359.

SANTOS, D. V.; LEMOS, F. C. S. Uma analítica da produção da mulher empoderada. Psicologia \& Sociedade, [S.1.], v. 23, n. 2, p. 407-414, 2011.

SILVA, T. T. A "nova" direita e as transformações na pedagogia da política e na política da pedagogia. In: GENTILI, P. A. A.; SILVA, T. T. da (Org.). Neoliberalismo, qualidade total e educação: visões críticas. 5. ed. Petrópolis, RJ: Vozes, 1994. p. 11-27.

Recebido em: 30 de março de 2015 Aceito em: 3 de setembro de 2015 